\title{
Static and Dynamic Thermophysical Property Measurements at High Temperatures
}

\author{
S. Seetharaman, Du Sichen, R. Eriksson and E. Kapilashrami \\ Division of Metallurgy, Royal Institute of Technology, \\ SE-100 44 Stockholm, Sweden
}

\begin{abstract}
In view of the importance of generating reliable and self consistent thermophysical data, efforts have been made in the Division of Metallurgy, Royal Institute of Technology, Stockholm to measure the viscosities and thermal diffusivities of multicomponent slags as well as surface- and interfacial tensions. The measurements were also carried out in the dynamic mode to monitor high temperature reactions and understand the underlying mechanisms. In the latter case, the rate of dissolution of alumina in a slag as well as the rate of oxidation of $\mathrm{Fe}^{2+}$ in a fayalite slag were followed by measuring the viscosities along the reaction coordinate. The reaction rate between liquid iron with different oxygen levels and alumina/silica substrates was studied by the sessile-drop method. The paper illustrates the usefulness of this approach in understanding high temperature phenomena.
\end{abstract}

\section{INTRODUCTION}

Modelling of high temperature processes requires access to reliable thermophysical properties of high temperature systems that are relevant to heat- and mass transfer computations. A priori estimations of the thermophysical properties have often been found to be limited to specific temperature and compositional ranges and we still have far to go to reach a unified picture of the structure of the system and its properties. As regards experimental measurements, the property data often need to satisfy the requirements of internal consistency and reliability with respect to extrapolations to temperature and compositional regions beyond the ranges of measurements. These, in turn, would necessitate accurate experimental measurements under well-controlled conditions and reliable property models that extrapolate the data as functions of temperature and composition.

In recent years, the change in system properties along the reaction coordinate has led to the monitoring of the reaction by following a specific property. The classical DTA or TGA techniques are typical examples of this type of experimentation. As long ago as 1957, Kozakevitch /I/ followed desulphurization reaction by observing the interfacial tension. This was followed by a more recent investigation on desulphurization by Gaye et al., /2/ sulphur transfer through the slag by Jakobsson et al. /3/ and dephosphorization by Jakobsson et al. /4\% In recent years, Sridhar and Cramb, 15-8/ along with other co-workers, combined this type of experimentation with in-situ observations to achieve a fundamental understanding of the kinetics of some of the important reactions with reference to steelmaking. The present paper puts forward the results of the monitoring of the physical properties in dynamic mode, carried out at the Royal Institute of Technology, Stockholm, with a view to understanding the reaction mechanisms.

The properties focused upon in the present paper are slag viscosities, thermal diffusivities and slag-metalrefractory interfacial properties. Measurements in the dynamic mode with respect to viscosity as well as contact angle changes with reactions are also highlighted. 


\section{STATIC MEASUREMENTS}

Static measurements refer to the properties of the system with temperature and compositional variables well defined. The Division of Metallurgy, Royal Institute of Technology has been focusing its efforts on accurate measurements of viscosities and thermal diffusivities of slag systems and surface/interfacial tensions in systems involving slags and liquid iron.

\subsection{Viscosity Measurements}

The Division of Metallurgy at the Royal Institute of Technology, Stockholm has been concentrating on generating self-consistent viscosity data for slag systems with the components $\mathrm{CaO}-\mathrm{MgO}-\mathrm{MnO}-\mathrm{FeO}-\mathrm{Al}_{2} \mathrm{O}_{3}-\mathrm{SiO}_{2}$. The well-established rotating-cylinder method was employed in the viscosity measurements. The preparation of the slags, the experimental setup as well as the procedure adopted for viscosity measurements under equilibrium conditions have been described in detail in earlier publications $/ 9 /$. The results have been incorporated into a pseudo-thermodynamic model description that enables reliable extrapolation of the data into temperature and composition domains not covered by experimentation $/ 10 \%$. One of the interesting systems for which the viscosities were measured was the ternary $\mathrm{CaO}-\mathrm{FeO}-\mathrm{Al}_{2} \mathrm{O}_{3} / 11 \%$ A second derivative analysis $/ 12 /$ of the viscosity data indicated the existence of a ternary compound in the system. This was confirmed by further experimentation /13/.

The viscosity measurements were extended to slag systems containing $\mathrm{CaF}_{2}$ as a slag component /14-19/. These systems are extremely interesting in view of their relevance to mould fluxes. The slag systems studied were based on the complex system $\mathrm{CaO}-\mathrm{FeO}-\mathrm{SiO}_{2}-\mathrm{CaF}_{2}$ /19/. The compositional changes were ascertained by pre- and post measurement chemical analyses. In all the experiments, the total experimental uncertainty is estimated to be less than $10 \%$. The pseudothermodynamic model / $10 /$ for viscosity descriptions of slags mentioned earlier was extended to those containing $\mathrm{CaF}_{2}$ as a component. In this case, F- $-\mathrm{O}^{2}$ interactions are introduced in the presence of different cations. As an example, Fig. 1 shows the estimated

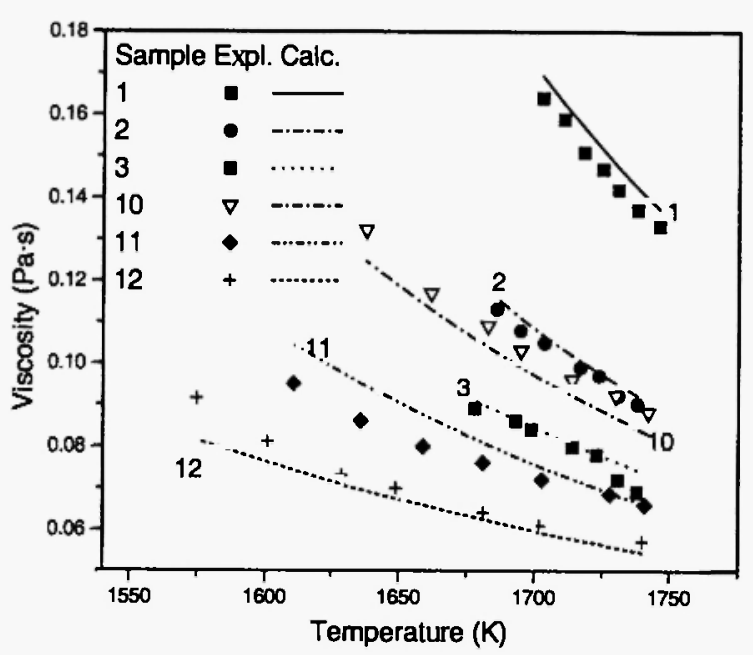

Fig. 1: Comparison of the calculated viscosities with the experimental data for " $\mathrm{FeO}$ "- $\mathrm{SiO}_{2}-\mathrm{CaF}_{2}$ slags $/ 19 /$.

viscosities as a function of temperature for a number of FeO- $\mathrm{SiO}_{2}-\mathrm{CaF}_{2}$ slags. The experimental data are also included in the same figure for comparison. It is seen that the experimental results are generally well reproduced by the model calculation.

\subsection{Thermal Diffusivity Measurements}

In an attempt to systematize the knowledge on the heat conduction of liquid silicates, the thermal diffusivities of some synthetic slags containing $\mathrm{CaO}$, $\mathrm{Al}_{2} \mathrm{O}_{3}$ and $\mathrm{SiO}_{2}$ have been measured, using the laser flash method in the temperature range $1625-1825 \mathrm{~K}$ $120 \%$ In this work, a three-layered sample cell arrangement was employed. In view of the uncertainties in the estimation of the thickness of the liquid slag films, a method in which two temperature response curves, originating from two separate laser pulses corresponding to two different sample thickness, with a known relative difference in thickness, has been employed.

A Sinku-Riko laser flash unit (model TC$7000 \mathrm{H} / \mathrm{MELT}$ ), with a maximum sample temperature limit of $1873 \mathrm{~K}$ was used for the present thermal diffusivity measurements. The furnace heating elements, eight in number, are made of lanthanum chromite. The sample was heated in argon atmosphere 
at the rate of $6 \mathrm{~K} \cdot \mathrm{mm}^{-i}$. During the course of the experiments, the temperature of the liquid sample was measured using a Pt-13\%Rh/Pt (R-type) thermocouple, calibrated periodically, positioned in an alumina tube, which, in turn, was placed in contact with the lower parts of the sample container. The operation of the three-layered laser flash method on the differential scheme was also confirmed by measuring the thermal diffusivity of liquid lithium nitrate $\left(\mathrm{LiNO}_{3}\right)$ in the temperature range 573-673 $\mathrm{K}$, using the measurement procedure described earlier.

The thermal diffusivity measurements by the laserflash method were carried out in the system $\mathrm{CaO}-\mathrm{Al}_{2} \mathrm{O}_{3}$ $\mathrm{SiO}_{2}$ keeping the $\mathrm{CaO} / \mathrm{Al}_{2} \mathrm{O}_{3}$ or $\mathrm{CaO} / \mathrm{SiO}_{2}$ ratio constant. In the present investigation, five different synthetic slag compositions have been studied. Figure 2 shows the effective thermal diffusivities of two different slags with constant $\mathrm{CaO} / \mathrm{Al}_{2} \mathrm{O}_{3}$ ratio of 2.59 . Slag 2 has a higher silica content. It is clearly seen that a marked difference in the diffusivity values could be noticed due to the increase of the silica network. At higher $\mathrm{CaO}$ contents, this behavior was less prevalent.

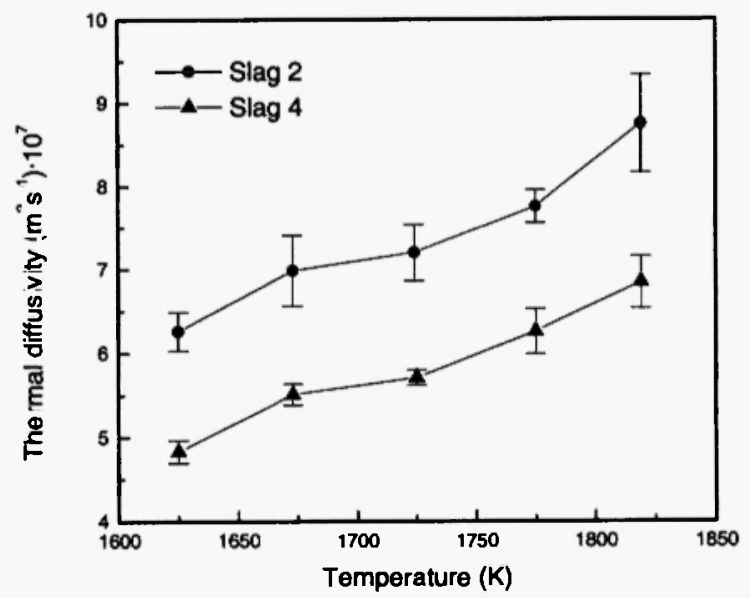

Fig. 2: Effective thermal diffusivities of two slags with differing $\mathrm{SiO}_{2}$ contents.

Figure 3 illustrates the effect of the increase in the alumina content in the same system at constant $\mathrm{CaO} / \mathrm{SiO}_{2}$ ratio of 0.93 . It is seen that an increase in the alumina content in the slag increases the effective thermal diffusivity by about $25 \%$. Correspondingly, the increase at higher silica contents was found to be as high as $50 \%$. These figures illustrate the effect of the

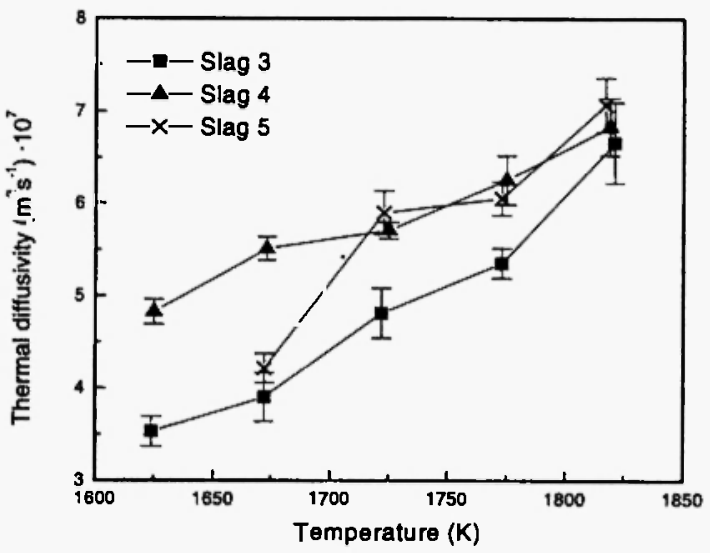

Fig. 3: Effective thermal diffusivities of three slags with differing $\mathrm{Al}_{2} \mathrm{O}_{3}$ contents.

silicate network on the thermal diffusivity of the slag. This was found even in the Arrhenius plots of the effective thermal diffusivities, which exhibit distinct slopes varying with composition.

It is seen in the above figures that the thermal diffusivities increase with temperature. This could be indicative of the photonic contribution to the conductivity. In order to investigate this aspect further, the thermal diffusivities of some of the above slag compositions were measured after adding different amounts of "FeO". This is shown in Fig. 4. The corrected values correspond to the radiation correction suggested by Waseda et al. $/ 21 /$ for slags with low amounts of "FeO".

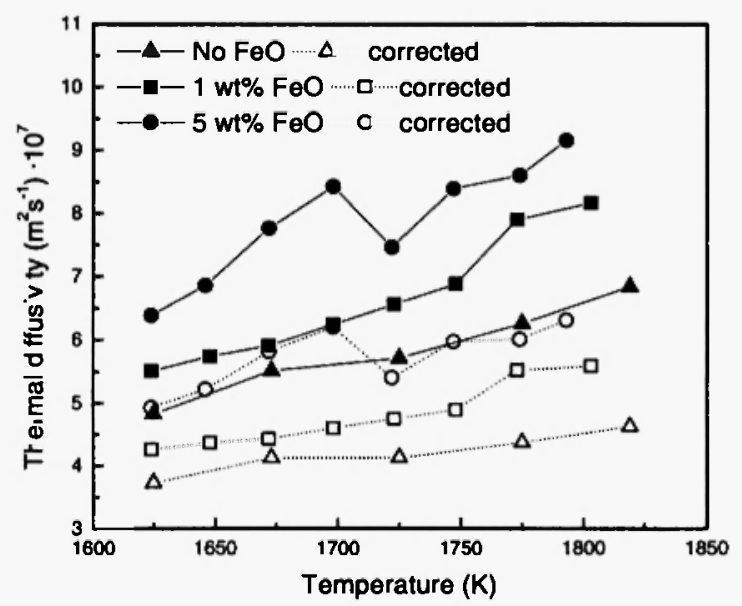

Fig. 4: Effect of addition of $\mathrm{FeO}$ on the effective thermal diffusivities of $\mathrm{CaO}-\mathrm{Al}_{2} \mathrm{O}_{3}-\mathrm{SiO}_{2}$ slags. 
It is seen that the effective thermal diffusivities are decreased markedly with $\mathrm{FeO}$ additions. It was difficult, however, to differentiate between the structural effects from the radiation contribution. Further work is presently being carried out in this regard.

\subsection{Surface and Interfacial Tension Measurements}

The Division of Metallurgy at the Royal Institute of Technology has an intensive program with respect to surface- and interfacial tension measurements. The surface tensions of $\mathrm{Cu}$ and $\mathrm{Ni}$ were measured under well-defined conditions towards establishing European standards $/ 22 /$. The surface tensions of $\mathrm{Fe}-\mathrm{O}$ as well as a few $\mathrm{Fe}$-O-S alloys were also determined /23/. Interfacial tensions of liquid iron in contact with some $\mathrm{CaO}-\mathrm{Al}_{2} \mathrm{O}_{3}$ $\mathrm{SiO}_{2}$ as well as $\mathrm{CaO}-\mathrm{FeO}-\mathrm{Al}_{2} \mathrm{O}_{3}-\mathrm{SiO}_{2}$ slags were also accurately determined.

\section{DYNAMIC MEASUREMENTS}

\subsection{Viscosity}

Three types of dynamic viscosity experiments were conducted, namely, (i) monitoring fluoride losses, (ii) monitoring alumina dissolution and (iii) oxidation of $\mathrm{Fe}^{2+}$ to $\mathrm{Fe}^{3+}$ in a fayalite slag. The first two experiments were specifically focused on the reactions of mould flux slags in the mould during continuous casting, wherein the viscosity is expected to increase due to both fluoride loss as well as the dissolution of alumina from the inclusions. The third series of experiments was of high relevance to copper metallurgy, wherein the oxidation of slag leads to an increase in the viscosity and consequent entrapment of the matte. In all these experiments, the crucible geometry as well as the gas flow rate were well defined. Further, extreme precautions were taken to purify the gases used. As a rule, the oxygen partial pressure in the exit gas was continuously monitored by means of a zirconia-calcia solid electrolyte galvanic cell maintained at $973 \mathrm{~K}$.

\subsubsection{Fluoride evaporation}

The gas flow pattern inside the reaction tube was computed for the boundary conditions existing during the viscosity measurements. For solving the NavierStokes equation, the commercial code FLUENT was used. By incorporating the vapor pressure data for $\mathrm{SiF}_{4}$ due to reactions with $\mathrm{SiO}_{2}$ in the slag, the concentration of $\mathrm{SiF}_{4}$ vapor at various levels could be mapped. This is shown in Fig. $5 / 15 /$. Similar calculations were carried out for $\mathrm{HF}$ vapor formed due to the reaction of $\mathrm{CaF}_{2}$ with moisture.

The major factor that could influence the fluoride loss would be higher equilibrium partial pressure. Thus, the thermodynamics of slags has an important role. The other factors that are identified are gas flow rate as well

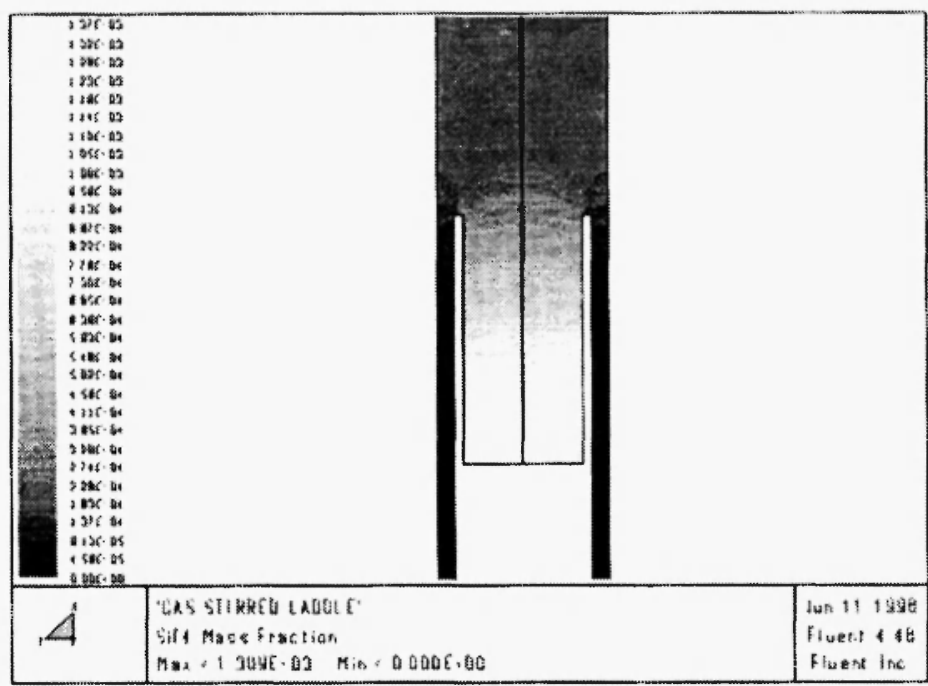

Fig. 5: Composition distribution of $\mathrm{SiF}_{4}$ at the vicinity of the crucible. 
as crucible heights.

In a further experiment, the changes in the viscosities of two $\mathrm{CaO}-\mathrm{FeO}-\mathrm{SiO}_{2}-\mathrm{CaF}_{2}$ slags were monitored over an extended period of time at 1741 and $1757 \mathrm{~K}$ by following the viscosity changes $/ 16 /$. The results are presented in Fig. 6.

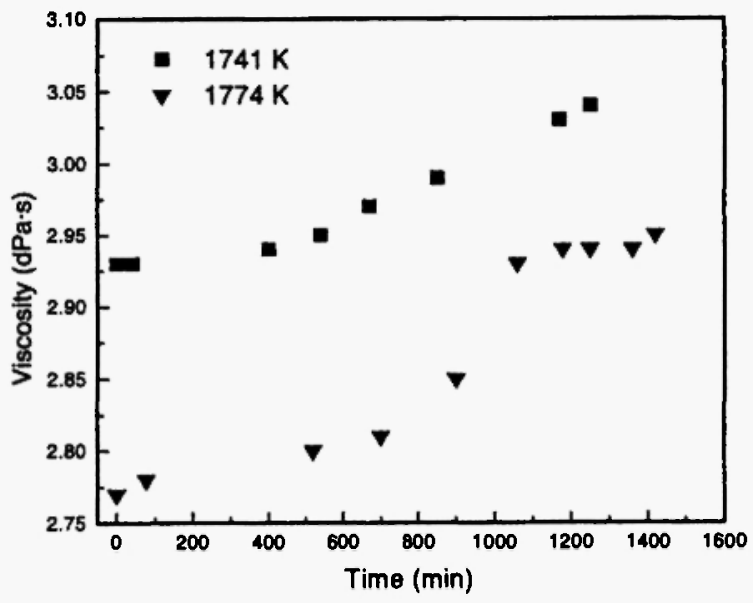

Fig. 6: The change of slag viscosity as a function of time due to the evaporation of fluoride in the case of a $\mathrm{CaO}-\mathrm{FeO}-\mathrm{SiO}_{2}-\mathrm{CaF}_{2}$ slag.

It is seen that, while the viscosity values show a slight tendency to increase with time, the changes are less than $5 \%$ of the measured values, which is still within the experimental uncertainties. This would imply that the consequences of fluoride loss from the mould flux slag may not be serious under similar conditions.

\subsubsection{Alumina dissolution}

In experiments aimed at following the alumina dissolution $/ 16 /$, an $\mathrm{Al}_{2} \mathrm{O}_{3}$ disc, $6 \mathrm{~mm}$ in thickness, was fixed to the bottom of a crucible using three small iron pins. The pre-melted master slag was placed above the $\mathrm{Al}_{2} \mathrm{O}_{3}$ disc before the crucible was introduced into the reaction chamber. The crucible along with the master slag and the $\mathrm{Al}_{2} \mathrm{O}_{3}$ disc was heated to the experimental temperature in purified argon atmosphere. Viscosity of the melt was then measured as a function of time. The viscosity at the start of the measurements was in agreement with the viscosity values of the pre-melted slags without alumina, confirming thereby that the amount of $\mathrm{Al}_{2} \mathrm{O}_{3}$ dissolved in the slag during the heating stage was negligible.
Three $\mathrm{CaO}-\mathrm{FeO}-\mathrm{SiO}_{2}-\mathrm{CaF}_{2}$ master slags were prepared in order to study the variation of viscosity with the dissolution of alumina. The approximate composition of the slag used in these measurements was $40 \% \mathrm{CaO}, 5 \% \mathrm{FeO}, 50 \% \mathrm{SiO}_{2}$ and $5 \% \mathrm{CaF}_{2}$ all in wt \%. In the second set of experiments 10 wt $\% \mathrm{Al}_{2} \mathrm{O}_{3}$ was introduced replacing equal amounts of lime and silica. The compositions of the slags before and after viscosity measurements were determined at different temperatures by chemical analyses. A uniform slag composition along the length of the bob of the spindle was ascertained by sampling the slag at different heights.

The viscosities at $1714 \mathrm{~K}, 1740 \mathrm{~K}$ and $1757 \mathrm{~K}$ are plotted as functions of time in Fig. 7. The process was found to be controlled by dissolution of the protecting layer accompanied by the diffusion of $\mathrm{Al}_{2} \mathrm{O}_{3}$ into the slag after the initial stages. The rates of the dissolution process at $1714 \mathrm{~K}, 1740 \mathrm{~K}$ and $1757 \mathrm{~K}$ were evaluated using the data obtained between 200 and 700 minutes. An Arrhenius plot on the basis of the reaction rates reveals an apparent activation energy of $186 \mathrm{~kJ} \mathrm{~mole}^{-1}$ for the dissolution.

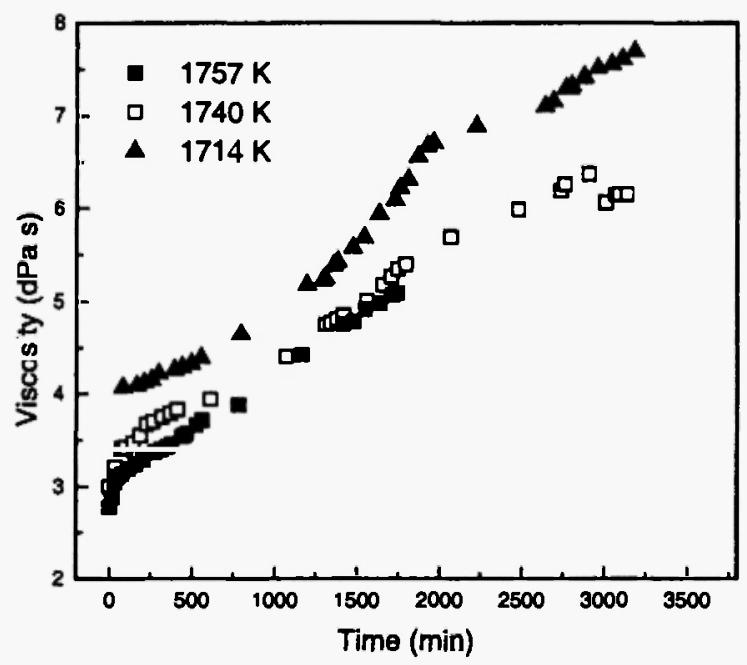

Fig. 7: The change of slag viscosities as a function of time due to alumina dissolution $/ 16 /$.

\subsubsection{Oxygen dissolution}

In this type of experiments, $\mathrm{CO} / \mathrm{CO}_{2}$ mixture was used to maintain oxidizing condition during dynamic viscosity measurements on Fe-O-Si slag. The gas flow 
rates were accurately controlled and monitored using flow controllers. The measurements were carried out on the binary $\mathrm{Fe}_{\mathrm{n}} \mathrm{O}-\mathrm{SiO}_{2}$ slag under argon atmosphere in a nickel crucible after validating their applicability by comparison with other crucible materials. The atmosphere was then switched to $\mathrm{CO}_{2} / \mathrm{CO}$ in order to measure the viscosity of slag under oxidizing conditions. With time, $\mathrm{CO}_{2}$ oxidizes the $\mathrm{Fe}^{2+}$ to $\mathrm{Fe}^{3+}$ and the slag composition changes and hence the viscosity. In the present work, the experimental temperatures were chosen to be $1673 \mathrm{~K}$ and $1623 \mathrm{~K}$. The ratio of $\mathrm{P}_{\mathrm{CO} 2}$ to $\mathrm{P}_{\mathrm{CO}}$ was 9.81 , which would lead to oxygen partial pressures of $2.5 \cdot 10^{-7}$ atmosphere at $1673 \mathrm{~K}$ and $7.2 \cdot 10^{-8}$ atmosphere at $1623 \mathrm{~K}$. The volume flow rates of $\mathrm{CO}$ and $\mathrm{CO}_{2}$ were chosen to be approximately 0.021 and 0.206 $\mathrm{N}$ liters/min. After viscosity measurements, the slag was cooled in argon atmosphere. Before and after viscosity measurements, slag samples were taken for chemical analysis.

As the oxidation progresses, the $\mathrm{Fe}^{3+}$ concentration in the slag increases and hence the viscosity varies with time. Fig. 8 shows the measured viscosity varying with time at 1673 and $1623 \mathrm{~K}$. It can be seen that reasonable reproducibility of measurements has been reached. The viscosity of the slag remains almost the same during the initial part of oxidation with a slight decrease at $1623 \mathrm{~K}$. At longer oxidation time, there is a sharp rise in viscosity. This rise in viscosity occurs earlier, at 1673 compared to that at 1623 .

Post-measurement sampling of the slag at different

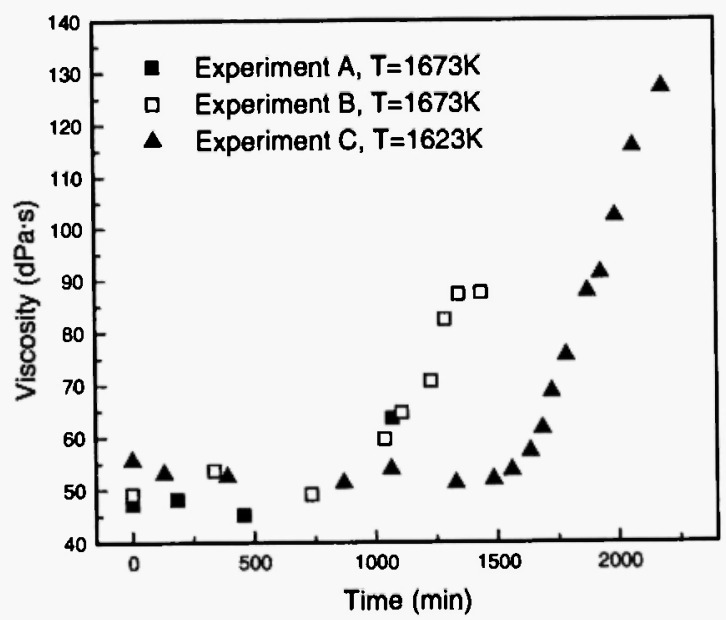

Fig. 8: Viscosity changes during the oxidation of a fayalite slag. heights showed that the slag compositions are fairly uniform along the height of the slag. A mathematical model incorporating the compositions obtained by analysis indicate that, when the mass fraction of the oxide with $\mathrm{Fe}^{3+}$ exceeds a mass fraction of 0.07 , the viscosity shows a sharp increase indicating the precipitation of magnetite.

\subsection{Surface Tension - Interfacial Tension Studies}

The variations of contact angle with time as an oxygen partial pressure is imposed over liquid iron in contact with alumina or silica substrates were examined in the dynamic mode in the $\mathrm{X}$-ray sessile-drop unit. The oxygen partial pressures were established by suitable gas mixtures containing $\mathrm{CO}, \mathrm{CO}_{2}$ and $\mathrm{Ar}$. The results of the experiment with liquid iron on alumina substrate at $1823 \mathrm{~K}$ with an imposed oxygen partial pressure of 3.0 $10^{-3} \mathrm{~Pa} / 24 /$ is presented in Fig. 9.

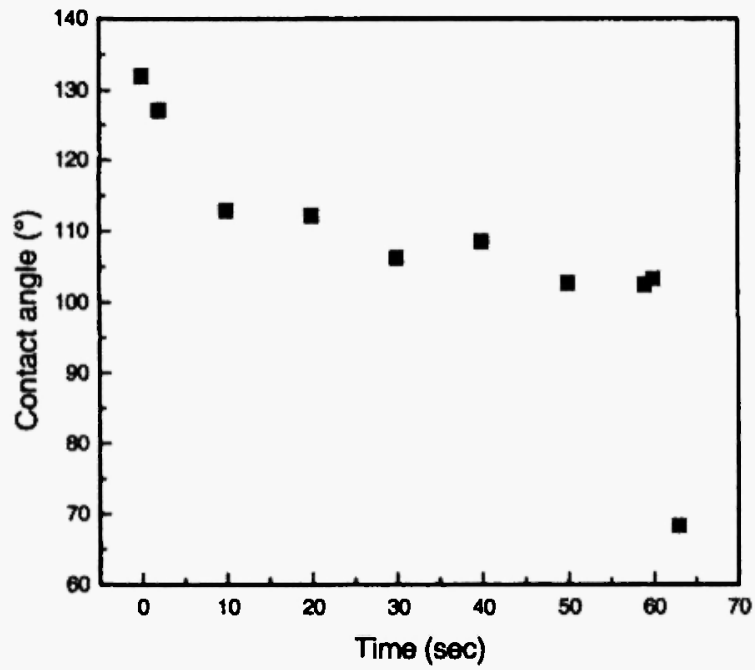

Fig. 9: The change of contact angle between iron drop and alumina substrate with time at $1823 \mathrm{~K}$ with an imposed oxygen partial pressure of $3.0 \cdot 10^{-3}$ $\mathrm{Pa}$.

It is very clearly seen that the contact angle, which is $135^{\prime \prime}$ at extremely low oxygen levels in the gas stream. shows an initial decrease as soon as the new, higher oxygen potential is imposed in the gas phase. This is followed by a plateau region with nearly constant 
contact angle, which is lower as the oxygen starts diffusing into the bulk. The oxygen reaching the bottom of the drop will lead to the formation of hercyanite. This reaction is at its maximum rate around $60 \mathrm{~s}$ marked by a steep drop of the contact angle. In the actual experiment, the drop attained non-wetting conditions with the completion of the formation of hercyanite and started moving due to imbalance in the surface forces.

The results with $\mathrm{SiO}_{2}$ substrate showed a somewhat similar trend as shown in Fig. 10. The oxygen partial pressure imposed was $1.5 \cdot 10^{2} \mathrm{~Pa}$ and the experiments were conducted at $1833 \mathrm{~K} / 25 /$.

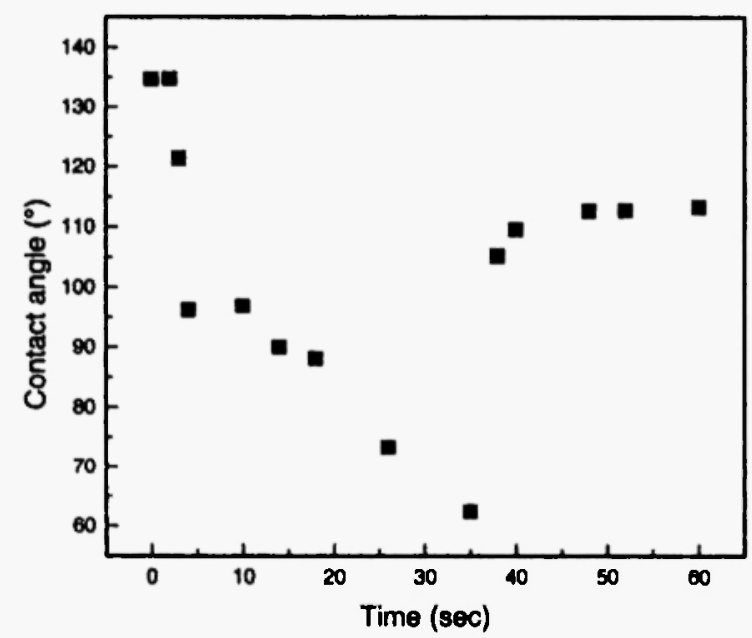

Fig. 10: The change of contact angle between iron drop and silica substrate with time at $1833 \mathrm{~K}$ with an imposed oxygen partial pressure of $1.5 \cdot 10^{-2} \mathrm{~Pa}$.

Dynamic interfacial studics have also been carried out with liquid iron on an alumina substrate, immersed in an alumina-salurated $\mathrm{CaO}-\mathrm{Al}_{2} \mathrm{O}_{3}-\mathrm{SiO}_{2}$ slag. Fixed oxygen and sulphur potentials were imposed in the gas atmosphere and the change of the drop shape with time was studied as sulphur got transferred from the gas phase to the metal through the slag phase. A suitable model was developed that enabled the computation of the surface velocity of sulphur on the drop as well as the rate of sulphurization of the metal. The surface velocities computed are plotted in Fig. 11.

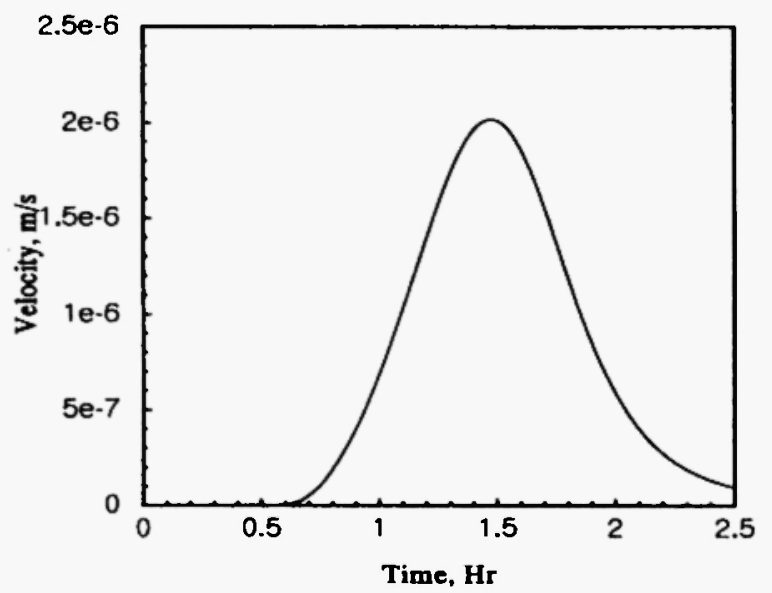

Fig. 11: Computed surface velocities as a function of time.

\section{SUMMARY}

The present paper describes the experimental studies carried out at the Division of Metallurgy, Royal Institute of Technology, Stockholm on the viscosities and thermal diffusivities of slags as well as surface/interfacial tensions. We aimed to achieve a set of self-consistent and reliable data that would be useful to the metallurgical process industry. Efforts were also directed towards understanding of the process phenomena by monitoring the change of the physical properties along the reaction coordinate. Fluoride losses, rate of dissolution of alumina as well as the rate of oxidation of $\mathrm{Fe}^{2+}$ with respect to the slag phase were followed by measuring the change of viscosities with time. Sulphur transfer from gas phase to iron immersed in slag was monitored by following the interfacial tension by the X-ray sessile drop method. The surface velocity was estimated from the results. The advantages of dynamic physical property studies are highlighted.

\section{REFERENCES}

1. P. Kozakevitch: Symp. on Phys. Chem. Steelmaking, MIT Press, 134 (1957).

2. H. Gaye, L. D. Lucas, M. Olette and P. V. Riboud: Can. Metall. Quart., 23、179-191 (1984).

3. A. Jakobsson, N. N. Viswanathan, Du Sichen and 
S. Seetharaman: Metall. Mater. Trans. B, 31B, 973-980 (2000).

4. A. Jakobsson, M. Nasu, J. Mangwiru, K. C. Mills and S. Seetharaman: Phil. Trans. R. Soc. Lond. A, 356, 995-1001 (1998).

5. Orrling, S. Sridhar and A. W. Cramb: High Temp. Mater. Proc., 20, 195-199 (2001).

6. S. Sridhar and A. W. Cramb: Metall. Mater. Trans. B, 31B, 406-410 (2000).

7. P. Misra, S. Sridhar and A. W. Cramb: Metall. Mater. Trans.B, 32B, 963-967 (2001).

8. P. Misra, V. Chevrier, S. Sridhar and A. W. Cramb: Metall. Mater. Trans., 31B, 1135-1139 (2000).

9. F. Ji: Ph. D. Thesis, Department of Metallurgy, Royal Institute of Technology, Stockholm, Sweden, (1998).

10. S. Seetharaman, Du Sichen and J. Y. Zhang:, $J$. Met., 51, 38-40 (1999).

11. B. Vidacak, Du Sichen and S. Seetharaman: Metall. Mater. Trans. B, 32B, 679-684 (2001).

12. S. Seetharaman, S. Sridhar, Du Sichen and K. C. Mills: Metall. Mater. Trans. B, 31B, 111-19 (2000).

13. B. Vidacak, Du Sichen and S. Seetharaman: ISIJ International, 42, 561-563 (2002).

14. F. Shahbazian, Du Sichen., K. C. Mills and S. Seetharaman: Ironmaking and Steelmaking, 26,
193-199 (1999).

15. F. Shahbazian, Du Sichen and S. Seetharaman: ISIJ International, 39, 687-696 (1999).

16. F. Shahbazian: Scandinavian Journal of Metallurgy, 30, 302-308 (2001).

17. F. Shahbazian: Ph. D. Thesis, Division of Metallurgy, Royal Institute of Technology, Stockholm, Sweden, (2001).

18. N. N. Viswanathan, F. Shahbazian, Du Sichen and S. Seetharaman: Steel Research, 70, 53-58 (1999).

19. F. Shahbazian, Du Sichen and S. Seetharaman: ISIJ International, 42, 155-162 (2002).

20. R. Eriksson and S. Seetharaman, Sent for publication to Metall. Mater. Trans.B, (2001).

21. Y. Waseda, M. Masuda, K. Watanabe, H. Shibata, H. Ohta and K. Nakajima: High Temp. Mater. Process., 13, 267-275 (1994).

22. R. F. Brooks, I. Egry, S. Seetharaman and D. Grant: $15^{\text {th }}$ ECTP Symposium, Wurzburg, Germany, Sept. (1999).

23. A. Jakobsson, N. N. Viswanathan, Du Sichen and S. Seetharaman: Metall. Mater. Trans.B, 31B, 973980 (2000).

24. Kapilashrami, A. K. Lahiri and S. Seetharaman: Sent for publication to Metall. Mater. Trans., (2001).

25. Kapilashrami, A. K. Lahiri, A. W. Cramb and S. Seetharaman: to be sent for publication. (2002). 